\title{
THE HEALTH CONSEQUENCES OF AERIAL SPRAYING OF ILLICIT CROPS: THE CASE OF COLOMBIA ${ }^{1}$
}

\author{
Adriana Camacho \\ Daniel Mejia ${ }^{3}$ \\ August 2012 \\ (Very preliminary and incomplete. Please do not cite)
}

\begin{abstract}
This paper exploits the variation in aerial spraying across time and space in Colombia and employs a panel of individual health records in order to study the causal effects of aerial spraying of herbicides (Glyphosate) on health-related outcomes. Our results show that an increase in the amount of aerial spraying in a municipality increases the number of medical consultations related to the exposure of Glyphosate that the municipality's inhabitants present. This finding is robust to the inclusion of individual fixed effects, which compares the prevalence of Glyphosate related consultations for the same person under different levels of exposure to the herbicide. We find strong negative effects on dermatological problems and abortions, while there is no evidence of effects on respiratory diseases.
\end{abstract}

JEL codes: I15, H75.

Key Words: Aerial spraying, eradication policies, health, Glyphosate.

\footnotetext{
${ }^{1}$ We thank Juan Pablo Cote and Lorena Caro for excellent research assistance. We thank the DFID for financial support. The usual caveat applies.

${ }^{2}$ Corresponding author. Associate Professor, Department of Economics, Universidad de los Andes. E-mail: adcamach@uniandes.edu.co

${ }_{3}^{3}$ Associate Professor and Director of the Research Center on Drugs and Security, Department of Economics, Universidad de los Andes. E-mail: dmejia@uniandes.edu.co. Daniel Mejia acknowledges the Ministerio de Protección Social for providing the RIPS data.
} 


\section{Introduction}

One of the main strategies of the anti-drug programs in producing countries such as Colombia, Mexico and Afghanistan, is the aerial spraying of herbicides aimed at destroying crops, the raw material of hard drug production ${ }^{4}$. Under the so-called Plan Colombia, for instance, the average annual number of hectares sprayed with herbicides during the last decade has been 128,000. At its peak, in 2006, 172,000 hectares were aerially sprayed with glyphosate (see Figure 1). The effectiveness of this approach has been thoroughly defended by the US and Colombian governments and heatedly attacked and questioned by NGOs and opponents of the so-called "war on drugs". Nevertheless, the debate about the effectiveness of aerial spraying campaigns and its collateral costs is often based on ideological grounds, and has very rarely taken the available and emerging scientific evidence seriously. However, both structural evaluations (Mejia and Restrepo, 2011) and reduced-form estimation techniques using arguably exogenous sources of variation (Reyes, 2011 and Mejia et al., 2012), indicate that aerial spraying campaigns of coca crops in Colombia are not effective strategies in reducing the levels of coca cultivation. On top of its ineffectiveness, this “chemical war”, as it has often been called by opponents of the war on drugs, has been blamed to generate all sorts of collateral negative effects. Among others, the distrust of local affected populations on State and Government institutions ${ }^{5}$, nonnegligible negative effects on the environment ${ }^{6}$ (especially on the amphibian populations through the contamination of water sources) and negative externalities on health. However, it is important to note that most of the evidence on these collateral effects comes from field work that is hard to generalize and to causally analyze. Field work and anecdotal evidence are plagued by confounding factors, coca cultivation itself being the most important one, and these factors make it difficult to blame aerial spraying as a direct cause of the mentioned maladies. More precisely, given the high spatial correlation between coca

\footnotetext{
${ }^{4}$ Poppy seeds in the case of heroin production and coca bushes in the case of cocaine production

${ }^{5}$ See Landy (1988), Navarrete-Frías et al. (2005), Felbab-Brown (2009) and García (2011), among others.

${ }^{6}$ See Relyea (2005), Navarrete-Frías et al. (2005), Cox (2005) and Imming (2010) for studies documenting the effects of aerial spraying with Glyphosate on the environment (deforestation, pollution of water sources, etc.) and on animal species.
} 
cultivation and the occurrence of aerial spraying campaigns, it is easily arguable that if coca cultivation and cocaine production themselves make indiscriminate use of pesticides and other agricultural inputs and chemical precursors, then these activities can be the ones generating the negative health and environmental consequences observed by NGOs in the field. In short, most of the evidence (anecdotal, from field work and empirical) is plagued by issues of endogeneity and confounding factors that have made it hard to reach conclusions regarding the effects of spraying campaigns on health outcomes.

In this paper we take the issue of endogeneity seriously and use a large administrative panel data set that contains individual health records, together with very precise information of aerial spraying events at a daily and municipal level, in order to disentangle the causal effect of aerial spraying of herbicides on a broad range of health outcomes. Our identification strategy relies on the fact that we observe individuals in our sample more than once, allowing us to compare the evolution of glyphosate-related diagnostics under different levels of exposure to aerial campaigns over time. Our data covers more than 50 million observations and 8 million individuals, as well as the number of square kilometers daily sprayed over a period of five years (between January 2003 and December 2007). We estimate individual fixed effects regressions of dermatological, respiratory diagnoses and abortions. The individual fixed effects specification allows us to compare the increase in the probability of having a health problem related to the aerial spraying of herbicides for the same individual, exposed to different levels of aerial spraying at different moments in time. Our findings indicate that aerial spraying of glyphosate increases the probability of having dermatological problems and abortions. These results are robust to different specifications of the empirical model and to the inclusion of a wide range of controls. We do not find any significant impact of aerial spraying on respiratory-related illnesses. It is important to highlight that given the nature of our data, we are unable to capture long-term effects that might translate into lower life expectancy, quality of life or productivity.

There are four main strengths and contributions of our paper relative to the existing literature. First, to the best of our knowledge, this is the first paper in the literature to take 
the issue of causality seriously when trying to estimate the effect of spraying of illicit crops on health outcomes in a drug-producing country. In particular, given that the exact timing and magnitude of spraying campaigns is difficult to be anticipated, spraying events are arguably an exogenous shock from the individuals' point of view. This allows us to have an appropriate quasi-experimental design to test the effects of aerial spraying on health outcomes. Second, the large sample size is an important strength of our paper, both in terms of the internal and external validity of our results. We use a dataset containing administrative records on all the health service institutions in Colombia from 2003 to 2007, accounting for more than 50 million visits to the doctor and approximately 2.5 million completed and non-completed birth registrations. The large sample size of our dataset also allows us to find very robust and precise results in the econometric specifications. Third, our data is appropriate for establishing a precise link between the date and magnitude of aerial spraying and the day in which individuals go to the hospital to see the doctor or visit the Emergency Room. Finally, the individual-level panel allows us to estimate an individual fixed-effects model that isolates genetic, behavioral and other unobserved individual characteristics that do not change over time. This is important in order to rule out confounding factors and omitted variable bias in our estimations.

The paper proceeds as follows. Section 2 reviews the relevant medical and epidemiological literature related to the effects of the exposure to herbicides on health outcomes. Section 3 describes the data in detail; Section 4 discusses the basic theoretical framework behind our empirical strategy. Section 5 reports and analyses the main results.

\section{A short review of the medical and epidemiological literature on the collateral effects of spraying campaigns on health outcomes}

A wide variety of medical studies have documented the negative impacts of glyphosate on human health. Sanborn et al. (2004) argue that aerial spraying generates dermatological problems in populations exposed to it; among these, they highlight burnings, irritations and skin redness. On the other hand, Sherret (2005) finds that the spraying of glyphosate is related to different respiratory diseases, mainly irritation of the lower respiratory tract and, 
sometimes, even lung cancer. Cox (1995) documents cases of poisoning in humans, with symptoms like gastrointestinal pain, vomiting, pulmonary dysfunction, destruction of red blood cells, gastrointestinal erosion, low blood pressure and kidney damage.

Some researchers have also addressed the effects of aerial spraying on abortions and fetus malformations. In particular, Sherret (2005) argues that pesticides affect the regulation of the embryonic cycle, which may result in abnormal fetus development. Studies by Sanborn et al. (2004), Regidor et al. (2004) and Sanborn et al. (2007) indicate that exposition to pesticides before conception is associated with abortions during the first trimester of pregnancy. They also indicate that the direct exposition of the father to large amounts of pesticides is linked to a greater risk of fetal death, effect that is larger if the exposition took place within a three months period preceding conception. Cases of anencephaly associated with direct exposition of the mother to pesticides during the preconception period (between the 3 months previous to the conception and the third month of pregnancy) have also been reported in the medical literature. Furthermore, the study developed by Sanborn et al. (2004) establishes that the exposition to the spraying of herbicides is associated with problems of fecundity and lower levels of sperm concentration.

Finally, the studies by Sanborn et al. (2004) and Sanborn et al. (2007) find (minor) evidence of the negative effect of exposure to glyphosate on the levels of depression, anxiety, neural disorders, minor tact sensibility, abnormal reflexes and psychomotor dysfunction. As to neurodegenerative diseases, they find evidence of a connection between the exposure to pesticides at work and Parkinson's and Alzheimer’s diseases later in life.

The contribution of our paper to the literature relies on the strong emphasis that we place on the empirical strategy. To the best of our knowledge, this is the first paper to take the potential endogeneity problem seriously when estimating the effect of aerial spraying of herbicides of illicit crops on health outcomes. While our results corroborate some of the results in the medical literature (e.g., the negative effects of exposure to glyphosate on dermatological problems and abortions), other negative effects, such as respiratory problems, are not found to be statistically significant in our estimations. 


\section{Data}

\subsection{RIPS database of medical consultations, emergency room visits and hospitalizations (2003 - 2007)}

The Individual Register of Health Services Provision (RIPS, as per the acronym in Spanish) contains the individual-level registers of medical consultations, Emergency Room (ER) visits, hospitalizations and procedures that took place in any health service institution in Colombia between 2003 and 2007. Each registry contains information about the appointment (date, municipality, diagnosis according to the ICD-10, institution that treated the patient and consultation fee) and about the patient (age, gender and type of health insurance). It is important to note that we do not have information or can infer anything about individuals that do not go to the doctor during the 5 years that correspond to our period of study and thus are not registered in the RIPS database.

Based on the medical literature summarized above, we construct three groups of diagnostics potentially related to aerial spraying ${ }^{7}$ : dermatologic, respiratory, and abortions. These three broad categories will be the main focus of our analysis. Each group collects a variety of diagnoses that were selected using the ICD-10 codes and in accordance with the medical literature findings. Table A1 includes a list of the diagnoses used in the estimations, as well as the proportion that each of them represents in the total number of events in our panel.

The upper panel from Table 1 and 2 shows descriptive statistics for the dependent variables in our dataset: dermatologic and respiratory medical consultations and abortions, respectively. More precisely, we create a dummy variable that equals 1 if the person appears in our panel with a glyphosate-related diagnosis, and 0 if the person appears in the panel with some other diagnosis. As shown in Table 1, dermatological and respiratory consultations related to aerial spraying correspond to approximately $2 \%$ and $5 \%$ of all reported diagnosis, respectively.

\footnotetext{
${ }^{7}$ We concentrate on health outcomes that appear in the short run (e.g., a few days or months after the exposition to herbicides). Other health-related problems that take more time to develop are left, for now, out of our analysis.
} 
With respect to abortions, these are severely underreported in our panel. As a result, we construct an abortion variable using information from prenatal care visits and hospitalizations related to births form the RIPS dataset. We assume that an abortion occurred if we see a mother attending a prenatal care visit, but we do not find a birth registered in the hospitalization sample later on. According to our measure, the average abortion rate is approximately 7\%, which is high compared to Latin American standards (4\% on average)). Although this is not a direct count of the real number of abortions, the correlation between our constructed measure of abortions and reported abortions at the municipal level is above 0.9. However, we should stress that our proposed measure does not take into account births that take place in locations different from hospitals, clinics and other formal medical institutions. Also, our measure assumes that all births are reported.

Other considerations regarding the cleaning process of our data are important to take into account. Appendix B includes a thorough description of the cleaning process, checks its representativeness and corrects for possible reporting mistakes.

\subsection{Aerial spraying and manual eradication data}

We have very detailed information on each event of aerial spraying of illicit crops and manual eradication campaigns for our study period. The data on spraying campaigns is recorded by geo-coding devices that are built-in in the aircrafts used for the aerial spraying campaigns. The information on the location (municipality) and number of hectares sprayed is recorded during the flight and then collected by the authorities when the plane lands. This information was obtained from the Anti-Narcotics Police, a special unit inside the Colombian National Police, which is in charge of designing and implementing most of the strategies used in the fight against illegal drug production and trafficking in the country. These records include the exact date and time of the spraying event, the municipality of occurrence, the number of hectares sprayed and the type of illicit crop sprayed (coca, marijuana or opium poppy). Manual eradication campaigns are recorded (also with geocoded devices) by the authorities in charge of implementing them (Grupos Móviles de 
Erradicación - Mobile Eradication groups). The data also includes the date of the event, the location (municipality), the number of hectares manually eradicated and the type of illicit crop.

\subsection{Municipal controls}

In all our estimations we control for a broad range of variables at the municipal level. These controls come from a municipal panel constructed by CEDE (Research Center on Economic and Development Studies of Universidad de los Andes), which provides information on economic, geographical and social characteristics at the municipal level in Colombia. Some of the variables that we control for include: population, tax revenues and Central Government expenditures on health. The inclusion of these variables in our estimations is important because they can affect health outcomes, and thus omitting them may lead to biased estimates of our coefficients of interest. We also control for other types of anti-narcotics policies, such as the detection and dismantling of cocaine processing facilities and the seizures of chemical precursors used in the production of cocaine. This information is also provided by the Colombian Anti-Narcotics Police.

It is worth noting that all our estimations control for the size of coca cultivation present in the municipality. If coca cultivation and aerial spraying are positively correlated (as it is indeed the case), controlling for the level of coca cultivation is important to prevent the estimation of our coefficient of interest from being biased.

\section{Health production function and empirical specification}

The general health production function in the economics literature was first introduced by Grossman (1972). Under this approach, health is assumed to be a function of several factors. The first one is the baseline health status of the individual, which corresponds to genetic factors. The second factor is leisure, understood as time spent on activities that improve health conditions such as exercising, cooking and sleeping, among others. The third factor is medical care. This factor corresponds to goods and services that individuals 
can purchase in order to improve their health, for example good quality of doctors, hospitals, medicines, vaccines and healthy food.

While it is extremely difficult to measure the baseline health status, we deal with it by exploiting the panel structure of our data and using individual fixed effects in our estimations. Fixed effects account for all individual characteristics that do not change over the period of our study (e.g., genetics, previous investments, health conditions, health care when young, etc.). This empirical strategy represents an advantage in comparison to cross sectional studies that compare unrelated individuals for whom these factors cannot be accounted for.

Instead of trying to estimate a structural form of the health production function, we estimate a reduced form of the following health production function:

$$
h_{i m t}=\Gamma\left(Y_{i t}, l_{i t}, u_{i}, s_{m t}\right)
$$

Where the subscript $i$ refers to the individual, $m$ to the municipality, and $t$ to the time period. $h$ is a dummy variable that takes the value of 1 if individual $i$ appears in the panel in municipality $m$ and at time $t$ suffering from a glyphosate-related diagnosis and 0 if it appears in the panel for any other diagnose. $Y$ are goods that can affect health; $l$ correspond to health inputs that require time; $u$ is an individual health endowment; and $s$ an environmental shock that, in our case, corresponds to the event of being exposed to aerial spraying in the municipality of residence.

For this setup to be understood as a quasi-experiment, or, in other words, for aerial spraying to be exogenous, we need to assume orthogonality between $s$, the environmental shock, and the error term. In this case, we are assuming that individuals cannot anticipate with certainty the time and extent of the spraying campaigns. By controlling for characteristics at the municipal level and using municipality or individual fixed effects, there should be very few concerns about the systematic variation between violence and other characteristics that will bias the estimations of our coefficients of interest. 
The reduced form linear relation of our preferred specification of the health production function will be the following linear probability model:

$$
h_{i m t}=\beta_{0}+\beta_{1} s_{m t}+\beta_{2} X_{i m t}+\beta_{3} Z_{m t}+\gamma_{\text {year }}+\gamma_{\text {month }}+\gamma_{i}+\varepsilon_{\text {imt }}
$$

$\beta_{1}$ is the coefficient associated with our variable of interest, the amount of aerial spraying, s. This variable is measured as the average area (in square Kilometers) sprayed during a certain period of time ${ }^{8}$ previous to a medical consultation that takes place at time $t . X_{i m t}$ and $Z_{m t}$ are individual and municipal controls that vary over time, respectively. Among the individual controls we include age, age square and type of health insurance. Similarly, we include municipal level controls, including population, area of the municipality, per capita tax revenues, per capita public expenditures on health services, proportion of municipal area cultivated with coca crops ${ }^{9}$, and a measure of the average area (in square Kilometers) of illicit crops that were manually eradicated during a certain period of time preceding the medical consultation. Including coca cultivation and manual eradication as controls is important in order to prevent our coefficient of interest from being biased. The high correlation between the extent of aerial spraying and coca cultivation at the municipal level (together with the fact that coca cultivation and cocaine production make indiscriminate use of pesticides, herbicides and chemical precursors) may create a spurious relationship between spraying campaigns and health outcomes if we didn't control for it in our estimations. We also include year, $\gamma_{\text {year }}$, and month, $\gamma_{\text {month }}$, dummies to control for unobservable factors changing over time, such as seasonal patterns of diseases. $\gamma_{i}$ are fixed effects that control for all unobservable factors varying across individuals that are constant over time. The individual fixed effect model in equation (3) is our preferred specification. This specification compares the health outcomes for a given individual when exposed to different levels of aerial spraying at different points in time. As explained before, this identification strategy improves over cross sectional studies that include municipality fixed

\footnotetext{
${ }^{9}$ Total coca cultivation in Colombia is measured every year in December (UNOCD and Government of Colombia, 2011). Therefore, we calculate the proportion of municipal area cultivated with coca as the average of the current and previous year cultivation, which would correspond to the initial and final measure of area cultivated for the year of study.
} 
effects, which require very strong assumptions about shocks being equally perceived by individuals or about shocks being homogeneous across all individuals in a given municipality. $\varepsilon_{i m t}$ is an error term assumed to be orthogonal to the probability of suffering from a glyphosate-related diagnosis $h$.

We restrict the time window between an aerial spraying event and a medical consultation to a given number of days ${ }^{10}$ in our baseline estimations. We also use an alternative way of measuring aerial spraying: instead of using the number of hectares sprayed in the municipality of residence 15 days prior to the medical consultation, we use a dummy that takes the value of one if there was a spraying event during the same time window. For dermatological and respiratory diagnoses we use a time window between the spraying event and the medical consultation of 15 days. In the case of abortions, we use eight (8) months prior to the last prenatal care visit. The reason for using this time window for the case of abortions is that the medical literature has found that the effect of aerial spraying on abortions can start up to three (3) months prior to conception and a loss is consider an abortion during the first five (5) months of pregnancy.

\section{Results}

We use three different dependent variables corresponding to medical diagnoses that have been identified in the medical literature to be related to the exposure to glyphosate in the short run. Tables 3, 4, and 5 present our baseline estimations of equation (2) for dermatological diagnoses, respiratory diagnoses, and abortions. All tables include six columns. Columns 1, 3 and 5 include year fixed effects, individual and municipal controls; columns 2, 4 and 6 include the controls from the previous columns plus individual fixed effects.

Table 3 reports the results for dermatological diagnoses. The first column in this table shows that, on average, a one square kilometer increase in the area sprayed with glyphosate increases by 0.7 percentage points the probability of having a dermatological problem during the following 15 days. Once individual fixed effects are included in this same

\footnotetext{
${ }^{10}$ The time window chosen is consistent with previous finding on the medical literature.
} 
regression, we find that the effect is reduced to 0.2 percentage points. The difference in the coefficients with these two sets of controls shows the relevance of including individual fixed effects, which capture heterogeneity among baseline health, behavior, and unobservable inputs that vary from person to person.

Columns 3 and 4 include a control for the proportion of the municipality area cultivated with coca. This control is very important since coca cultivation involves the use of pesticides and chemical precursors to transform coca leaf into coca base and cocaine, which may also have negative effects on individual's health. Columns 5 and 6 include manual eradication and show a negative and significant effect of the area of manual eradication on the probability of suffering from a dermatological problem. The magnitudes of the result described above for our variable of interest, area under aerial spraying, are robust to controlling for area cultivated with coca and area under manual eradication.

In order to check the robustness of our results, we consider a window of 30 days prior to the dermatological consultation. This window is longer than the time frame, of 15 days, that the medical literature has pointed out as the period when negative dermatological effects are detected due to the exposure to glyphosate. As expected, using this 30 day window there is no significant effect of aerial spraying over dermatological diagnoses. ${ }^{11}$

Table 4 reports results for respiratory diagnoses detected within a time frame of 15 days after the exposure to an aerial spraying event in the municipality of residence. Although the medical literature has argued that exposure to glyphosate causes respiratory problems, we do not find any evidence of this effect in our estimations. This result is robust to the inclusion of different controls, including the extent of coca cultivation in the municipality of residence and individual fixed effects.

Regarding abortions, our results, presented in Table 5, show that exposure to glyphosate between the three (3) months before conception and the five (5) months after conception, has a positive and significant impact on the probability of occurrence of an abortion. As mentioned before, our measure of abortions might be overestimated. For this reason we

\footnotetext{
${ }^{11}$ Results are not reported, but are available upon request.
} 
focus on the standardized coefficients of these regressions. The results from our preferred specification, including individual fixed effects, indicate that an increase of one standard deviation in the area sprayed in the municipality of residence increases the probability of an abortion by about 0.025 of a standard deviation.

\section{Placebo tests}

In an effort to evaluate the validity of our results, we estimate the baseline equation (2) for diagnoses that, in principle, is completely unrelated to spraying campaigns or coca cultivation, namely bone fractures. As shown in Table 6, the coefficients on spraying campaigns, coca cultivation and manual eradication are never statistically significant. This indicates that the results previously obtained do not seem to be spurious. 


\section{References}

Cox, C. (1995). Glyphosate, Part 1: Toxicology. Journal of Pesticide Reform, Vol. 15 No.3.

Cox, C. (1995). Glyphosate, Part 2: Human exposure and ecological effects. Journal of Presticide Reform Vol. 15 No. 4.

Dion, M., \& Russler, C. (2008). Eradication Efforts, the State, Displacement and Poverty: Explaining Coca Cultivation in Colombia During Plan Colombia. Journal of Latin American Studies, 40, 399-421.

Felbab-Brown, V. (2009). The Violent Drug Market in Mexico and Lessons from Colombia. Foreign Policy at BROOKINGS, Policy Paper No. 12.

Franz, J., Mao, M. K., \& Sikorki, J. A. (1997). Glyphosate: a unique global herbicide. Washington, D.C.: American Chemical Society.

Imming, J. (2010). Glyphosate: Safe of sorry. Organic Gardener.

Landy, D. S. (1988). The Constitutional Implications of Government Pesticide Spraying: The Case for Limited Judicial Intervention and an Intermediate Standard of Review. California Law Review Vol. 76 No. 1 , 221-264.

Navarrete-Frías, C., \& Thoumi, F. (2005). Illegal Drugs and Human Rights of Peasants and Indigenous Communities: The Case of Perú. Management of Social Transformations: Policy Papers 13.

Navarrete-Frías, C., \& Veillete, C. (2005). Drug crop eradication and alternative development in the Andes. Congressional Research Service.

Regidor, E., Ronda, E., García, A. M., \& Domínguez, V. (2004). Paternal exposure to agricultural pesticides and cause specific fetal death. Department of Preventive Medicine and Public Health, Universidad Complutense de Madrid.

Relyea, R. et al. (2006). The impact of insecticides and herbicides on biodiversity and productivity of aquatic communities. Ecological Applications Vol. 16 No. 5, 618627.

Reyes, L. C. (2011). Estimating the causal effect of forced eradication on coca cultivation in Colombian municipalities. MPRA Paper 33478, University Library of Munich, Germany. 
Sanborn, M., Cole, D., Kerr, K., Vakil, C., Sanin, H., \& Bassil, K. (2004). Systematic Review of Pesticide Human Health Effects. Ontario College of Familiary Physicians.

Sanborn, M., Cole, D., Kerr, K., Vakil, C., Sanin, H., \& K., B. (2007). Non-cancer health effects of pesticides. Ontario College of Familiary Physicians.

Sherret, L. (2005). Futility in Action: Coca Fumigation in Colombia. Journal of Drug. Vol. 35 No. 1, 151-168.

UNODC (United Nations Office against Drugs and Crime) \& Government of Colombia. (15 de Diciembre de 2011). Colombia: Monitoreo de cultivos de coca 2009. Obtenido de http://www.unodc.org/documents/cropmonitoring/Colombia/Colombia-Censo-2009-web.pdf 
Figure 1: Coca cultivation, aerial spraying and manual eradication in Colombia $2000-2008$

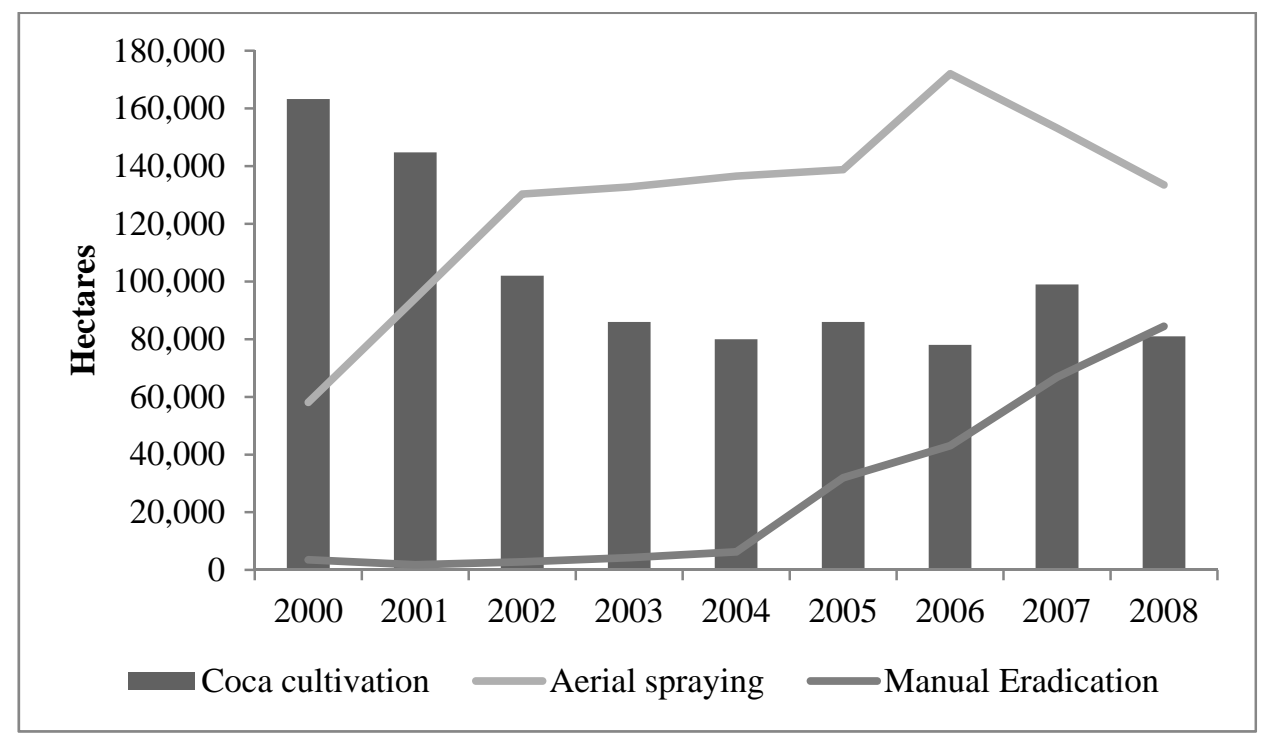


Table 1: Descriptive statistics, medical consultations panel

\begin{tabular}{lrrrcc}
\hline \hline Variable & Obs. & Mean & St. Dev. & Min. & Max. \\
\hline Dermatologic & $50,581,384$ & 0.01839 & 0.13436 & 0 & 1 \\
Respiratory & $50,581,384$ & 0.05378 & 0.22559 & 0 & 1 \\
\hline $\begin{array}{l}\text { Mean of the area under aerial spraying } \\
\text { in the last 15 days (in sq. km.) }\end{array}$ & $50,581,384$ & 0.00449 & 0.07027 & 0 & 4.53851 \\
$\begin{array}{l}\text { Proportion of municipal area cultivated } \\
\text { with coca }\end{array}$ & $50,581,384$ & 0.00030 & 0.00334 & 0 & 0.17271 \\
$\begin{array}{l}\text { Mean of the area under manual eradication } \\
\text { in the last 15 days (in sq. km.) }\end{array}$ & $50,581,384$ & 0.00078 & 0.01625 & 0 & 1.21582 \\
\hline \hline
\end{tabular}

Table 2: Descriptive statistics, abortions panel

\begin{tabular}{lccccc}
\hline \hline Variable & Obs. & Mean & St. Dev. & Min. & Max. \\
\hline Abortion & $2,716,563$ & 0.07231 & 0.25899 & 0 & 1 \\
& & & & & \\
\hline $\begin{array}{l}\text { Mean of the area under aerial spraying } \\
\text { in the 9 months considered (in sq. km.) }\end{array}$ & $2,716,563$ & 0.00474 & 0.03362 & 0 & 0.56003 \\
$\begin{array}{l}\text { Proportion of municipal area cultivated } \\
\text { with coca }\end{array}$ & $2,714,761$ & 0.00050 & 0.00449 & 0 & 0.17271 \\
$\begin{array}{l}\text { Mean of the area under manual eradication } \\
\text { in the 9 months considered (in sq. km.) }\end{array}$ & $2,716,563$ & 0.00142 & 0.01473 & 0 & 0.44011 \\
\hline \hline
\end{tabular}




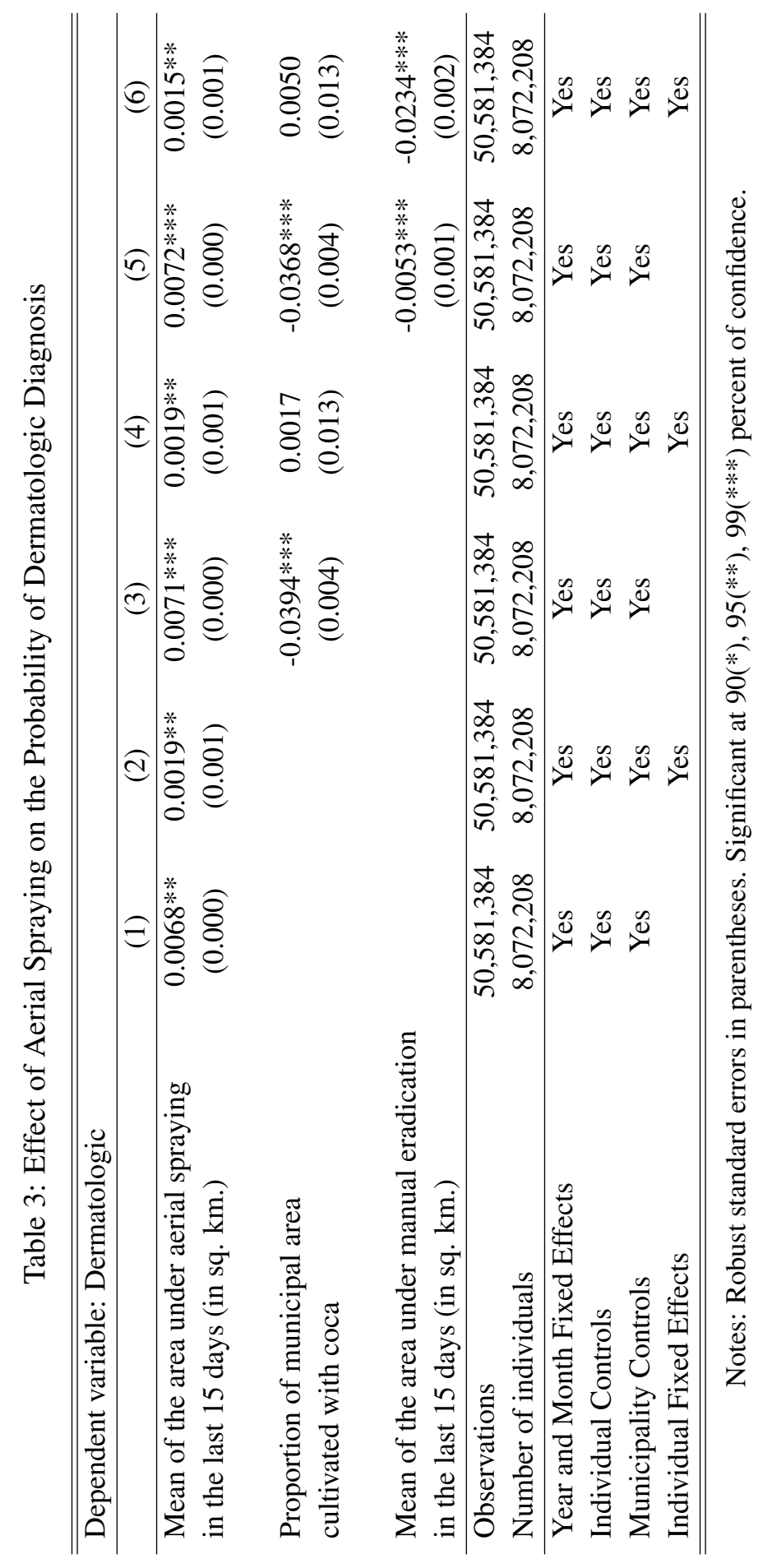




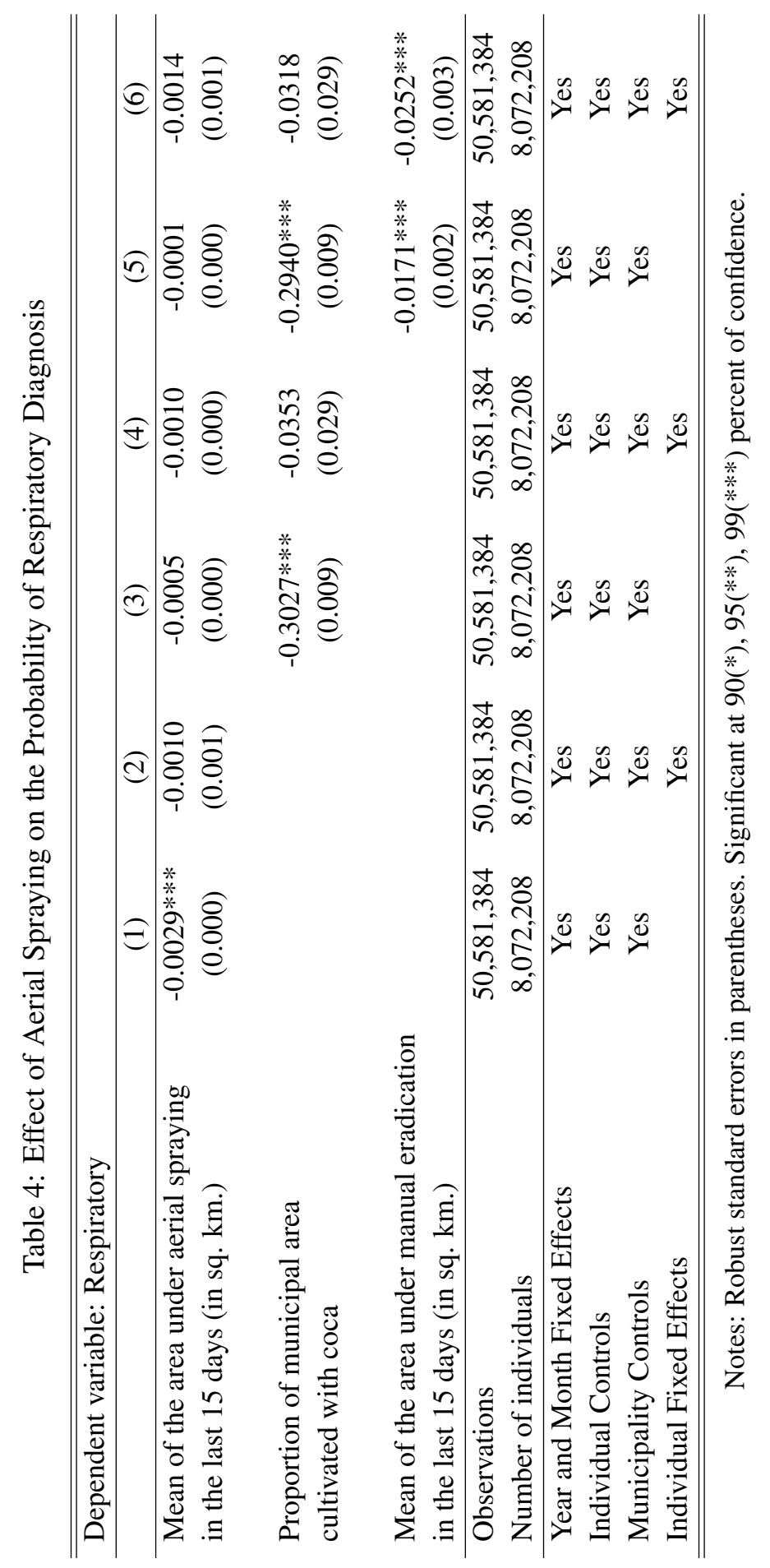




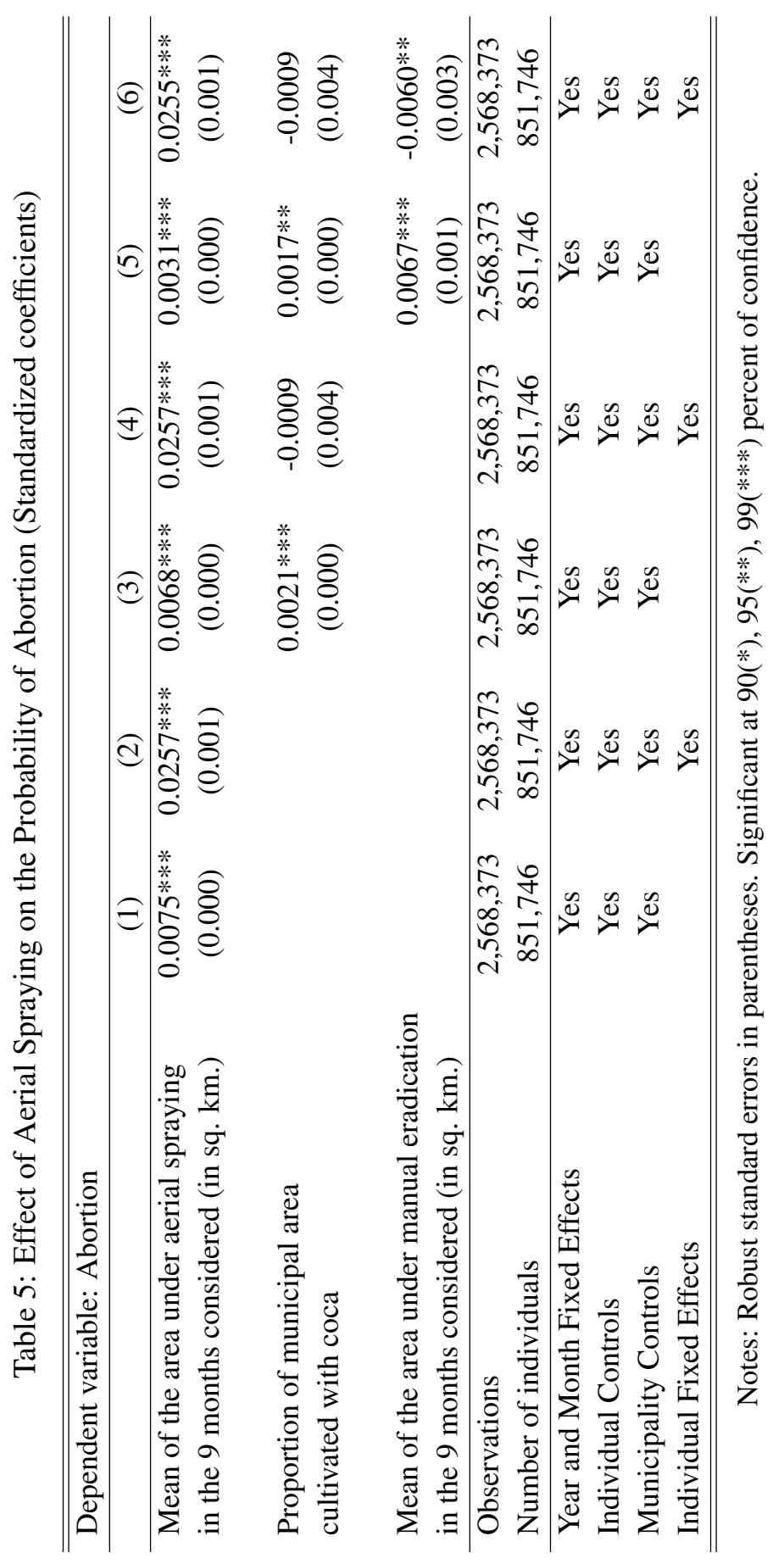




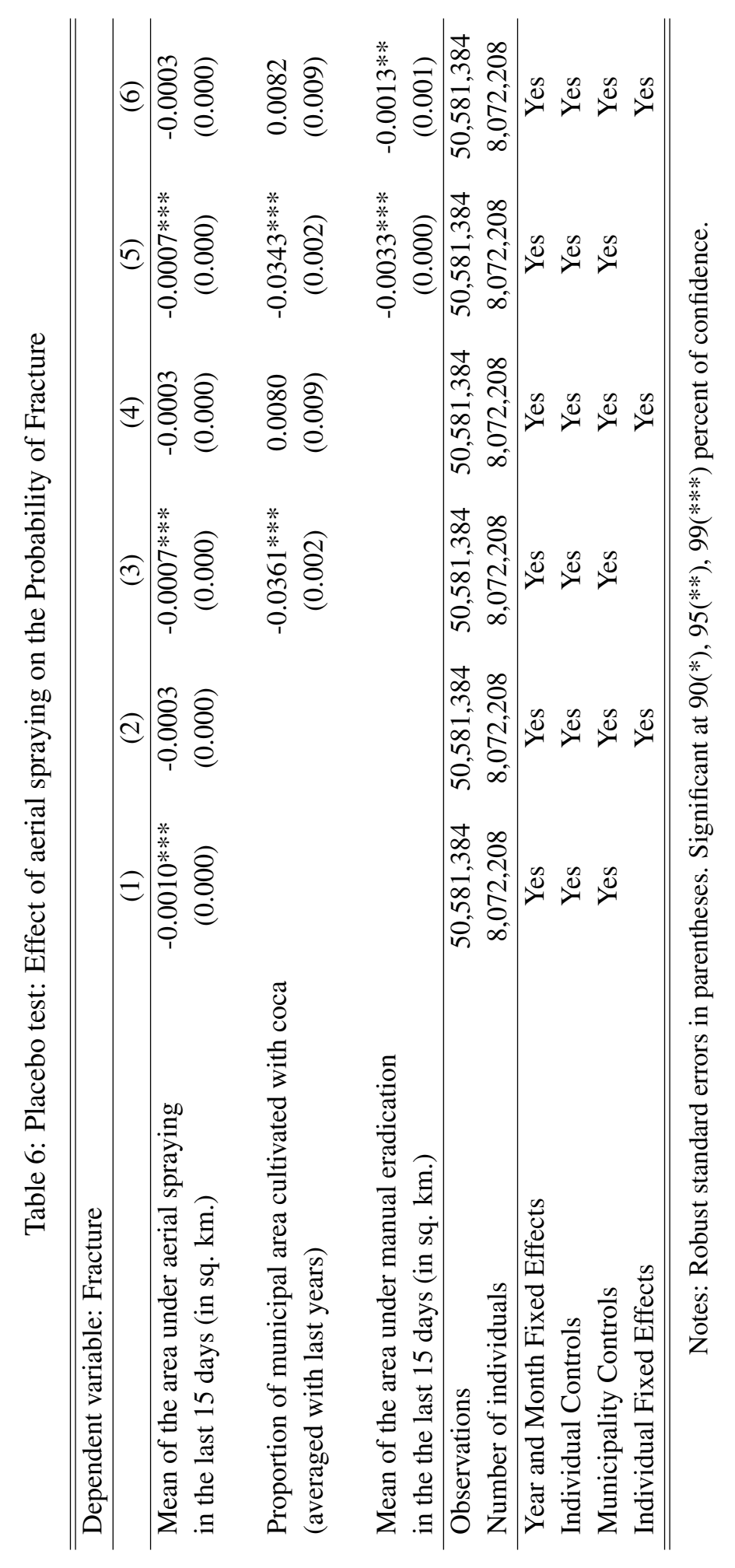


Appendix A. Diagnosis selected for the estimations and percentage that they represent from the total of consultations in the panel, by group of disease.

\begin{tabular}{|c|c|c|c|}
\hline \multicolumn{4}{|c|}{ Dermatologic diseases (L00-L99) } \\
\hline Code & Specification & $\begin{array}{l}\text { Proportion of } \\
\text { total diagnosis }\end{array}$ & $\begin{array}{c}\text { Proportion of total } \\
\text { dermatologic }\end{array}$ \\
\hline L10 & Pemphigus & $0.005 \%$ & $0.274 \%$ \\
\hline L11 & Other acantholytic disorders & $0.004 \%$ & $0.219 \%$ \\
\hline L12 & Pemphigoid & $0.001 \%$ & $0.055 \%$ \\
\hline L13 & Other bullous disorders & $0.003 \%$ & $0.164 \%$ \\
\hline L14 & Bullous disorders in diseases classified elsewhere & $0.000 \%$ & $0.000 \%$ \\
\hline $\mathbf{L 2 0}$ & Atopic dermatitis & $0.305 \%$ & $16.721 \%$ \\
\hline L21 & Seborrhoeic dermatitis & $0.069 \%$ & $3.783 \%$ \\
\hline L23 & Diaper [napkin] dermatitis & & \\
\hline L23.3 & Allergic contact dermatitis due to drugs in contact with skin & $0.003 \%$ & $0.164 \%$ \\
\hline L23.4 & Allergic contact dermatitis due to dyes & $0.002 \%$ & $0.110 \%$ \\
\hline L23.5 & Allergic contact dermatitis due to other chemical products & $0.005 \%$ & $0.274 \%$ \\
\hline L23.7 & Allergic contact dermatitis due to plants, except food & $0.002 \%$ & $0.110 \%$ \\
\hline L23.8 & Allergic contact dermatitis due to other agents & $0.027 \%$ & $1.480 \%$ \\
\hline L23.9 & Allergic contact dermatitis, unspecified cause & $0.182 \%$ & $9.978 \%$ \\
\hline L24 & Irritant contact dermatitis & & \\
\hline L24.0 & Irritant contact dermatitis due to detergents & $0.011 \%$ & $0.603 \%$ \\
\hline L24.1 & Irritant contact dermatitis due to oils and greases & $0.000 \%$ & $0.000 \%$ \\
\hline L24.2 & Irritant contact dermatitis due to solvents & $0.001 \%$ & $0.055 \%$ \\
\hline L24.4 & Irritant contact dermatitis due to drugs in contact with skin & $0.000 \%$ & $0.000 \%$ \\
\hline L24.5 & Irritant contact dermatitis due to other chemical products & $0.001 \%$ & $0.055 \%$ \\
\hline L24.7 & Irritant contact dermatitis due to plants, except food & $0.000 \%$ & $0.000 \%$ \\
\hline L24.8 & Irritant contact dermatitis due to other agents & $0.004 \%$ & $0.219 \%$ \\
\hline L24.9 & Irritant contact dermatitis, unspecified cause & $0.014 \%$ & $0.768 \%$ \\
\hline L25 & Unspecified contact dermatitis & & \\
\hline L25.1 & Unspecified contact dermatitis due to drugs in contact with skin & $0.001 \%$ & $0.055 \%$ \\
\hline L25.2 & Unspecified contact dermatitis due to dyes & $0.001 \%$ & $0.055 \%$ \\
\hline L25.3 & Unspecified contact dermatitis due to other chemical products & $0.007 \%$ & $0.384 \%$ \\
\hline L25.5 & Unspecified contact dermatitis due to plants, except food & $0.001 \%$ & $0.055 \%$ \\
\hline L25.8 & Unspecified contact dermatitis due to other agents & $0.004 \%$ & $0.219 \%$ \\
\hline L25.9 & Unspecified contact dermatitis, unspecified cause & $0.051 \%$ & $2.796 \%$ \\
\hline $\mathbf{L 2 6}$ & Exfoliative dermatitis & $0.002 \%$ & $0.110 \%$ \\
\hline L27 & Dermatitis due to substances taken internally & & \\
\hline L27.8 & Dermatitis due to other substances taken internally & $0.000 \%$ & $0.000 \%$ \\
\hline L27.9 & Dermatitis due to unspecified substance taken internally & $0.005 \%$ & $0.274 \%$ \\
\hline L28 & Lichen simplex chronicus and prurigo & $0.029 \%$ & $1.590 \%$ \\
\hline
\end{tabular}




\begin{tabular}{|c|c|c|c|}
\hline L29 & Pruritus & $0.030 \%$ & $1.645 \%$ \\
\hline L30 & Other dermatitis & $0.378 \%$ & $20.724 \%$ \\
\hline L40 & Psoriasis & $0.040 \%$ & $2.193 \%$ \\
\hline L41 & Parapsoriasis & $0.003 \%$ & $0.164 \%$ \\
\hline L42 & Pityriasis rosea & $0.005 \%$ & $0.274 \%$ \\
\hline L43 & Lichen planus & $0.008 \%$ & $0.439 \%$ \\
\hline L44 & Other papulosquamous disorders & & \\
\hline L44.0 & Pityriasis rubra pilaris & $0.001 \%$ & $0.055 \%$ \\
\hline L45 & Papulosquamous disorders in diseases classified elsewhere & $0.000 \%$ & $0.000 \%$ \\
\hline $\mathbf{L} 50$ & Urticaria & $0.223 \%$ & $12.226 \%$ \\
\hline L51 & Erythema multiforme & $0.003 \%$ & $0.164 \%$ \\
\hline L52 & Erythema nodosum & $0.003 \%$ & $0.164 \%$ \\
\hline L53 & Other erythematous conditions & $0.004 \%$ & $0.219 \%$ \\
\hline L54 & Erythema in diseases classified elsewhere & $0.001 \%$ & $0.055 \%$ \\
\hline L55 & Sunburn & $0.005 \%$ & $0.274 \%$ \\
\hline L56 & Other acute skin changes due to ultraviolet radiation & $0.007 \%$ & $0.384 \%$ \\
\hline L63 & Alopecia areata & $0.024 \%$ & $1.316 \%$ \\
\hline L64 & Androgenic alopecia & $0.012 \%$ & $0.658 \%$ \\
\hline L65 & Other nonscarring hair loss & $0.007 \%$ & $0.384 \%$ \\
\hline L66 & Cicatricial alopecia [scarring hair loss] & $0.006 \%$ & $0.329 \%$ \\
\hline L67 & Hair colour and hair shaft abnormalities & $0.000 \%$ & $0.000 \%$ \\
\hline L68 & Hypertrichosis & $0.003 \%$ & $0.164 \%$ \\
\hline L70 & Acne & & \\
\hline L70.8 & Other acne & $0.011 \%$ & $0.603 \%$ \\
\hline L71 & Rosacea & $0.014 \%$ & $0.768 \%$ \\
\hline $\mathbf{L 8 0}$ & Vitiligo & $0.017 \%$ & $0.932 \%$ \\
\hline L81 & Other disorders of pigmentation & $0.054 \%$ & $2.961 \%$ \\
\hline L82 & Seborrhoeic keratosis & $0.018 \%$ & $0.987 \%$ \\
\hline L83 & Acanthosis nigricans & $0.001 \%$ & $0.055 \%$ \\
\hline L84 & Corns and callosities & $0.017 \%$ & $0.932 \%$ \\
\hline L85 & Other epidermal thickening & $0.010 \%$ & $0.548 \%$ \\
\hline L86 & Keratoderma in diseases classified elsewhere & $0.000 \%$ & $0.000 \%$ \\
\hline L87 & Transepidermal elimination disorders & $0.001 \%$ & $0.055 \%$ \\
\hline L88 & Pyoderma gangrenosum & $0.000 \%$ & $0.000 \%$ \\
\hline L89 & Decubitus ulcer and pressure area & $0.005 \%$ & $0.274 \%$ \\
\hline L90 & Atrophic disorders of skin & $0.013 \%$ & $0.713 \%$ \\
\hline L91 & Hypertrophic disorders of skin & $0.028 \%$ & $1.535 \%$ \\
\hline L92 & Granulomatous disorders of skin and subcutaneous tissue & $0.013 \%$ & $0.713 \%$ \\
\hline L93 & Lupus erythematosus & $0.011 \%$ & $0.603 \%$ \\
\hline L94 & Other localized connective tissue disorders & $0.007 \%$ & $0.384 \%$ \\
\hline L95 & Vasculitis limited to skin, not elsewhere classified & $0.004 \%$ & $0.219 \%$ \\
\hline L97 & Ulcer of lower limb, not elsewhere classified & $0.019 \%$ & $1.042 \%$ \\
\hline
\end{tabular}




\begin{tabular}{|c|c|c|c|}
\hline L98 & $\begin{array}{l}\text { Other disorders of skin and subcutaneous tissue, not } \\
\text { elsewhere classified } \\
\text { Other disorders of skin and subcutaneous tissue in diseases } \\
\text { classified elsewhere }\end{array}$ & $0.059 \%$ & $3.235 \%$ \\
\hline \multicolumn{2}{|r|}{ Total Dermatologic } & $1.824 \%$ & $100 \%$ \\
\hline
\end{tabular}

\begin{tabular}{|c|l|c|c|}
\hline \multicolumn{3}{|c|}{ Respiratory diseases (J00-J99) } \\
\hline Code & \multicolumn{1}{|c|}{ Specification } & $\begin{array}{c}\text { Proportion of } \\
\text { the total of } \\
\text { consultations }\end{array}$ & $\begin{array}{c}\text { Proportion of the } \\
\text { total of respiratory } \\
\text { consultations }\end{array}$ \\
\hline J00 & Acute nasopharyngitis [common cold] & $2.183 \%$ & $40.926 \%$ \\
J01 & Acute sinusitis & $0.383 \%$ & $7.180 \%$ \\
J02 & Acute pharyngitis & $0.824 \%$ & $15.448 \%$ \\
J30 & Vasomotor and allergic rhinitis & $0.500 \%$ & $9.374 \%$ \\
J31 & Chronic rhinitis, nasopharyngitis and pharyngitis & $0.151 \%$ & $2.831 \%$ \\
J32 & Chronic sinusitis & $0.108 \%$ & $2.025 \%$ \\
J33 & Nasal polyp & $0.012 \%$ & $0.225 \%$ \\
J34 & Other disorders of nose and nasal sinuses & $0.112 \%$ & $2.100 \%$ \\
J36 & Peritonsillar abscess & $0.006 \%$ & $0.112 \%$ \\
J37 & Chronic laryngitis and laryngotracheitis & $0.031 \%$ & $0.581 \%$ \\
J38 & Diseases of vocal cords and larynx, not elsewhere classified & $0.012 \%$ & $0.225 \%$ \\
J39 & Other diseases of upper respiratory tract & $0.068 \%$ & $1.275 \%$ \\
J45 & Asthma & $0.708 \%$ & $13.273 \%$ \\
J46 & Status asthmaticus & $0.070 \%$ & $1.312 \%$ \\
J68 & Respiratory conditions due to inhalation of chemicals, gases, & $0.005 \%$ & $0.094 \%$ \\
J81 & fumes and vapours & & \\
J96 & Respiratory failure, not elsewhere classified & $0.003 \%$ & $0.056 \%$ \\
R05 & Cough & $0.032 \%$ & $0.600 \%$ \\
\hline & \multicolumn{1}{|c|}{ Total Respiratory } & $0.126 \%$ & $2.362 \%$ \\
\hline
\end{tabular}

\begin{tabular}{|c|l|c|c|}
\hline \multicolumn{2}{|c|}{ Eyes diseases (H00-H59) } \\
\hline Code & \multicolumn{1}{|c|}{ Specification } & $\begin{array}{c}\text { Proportion of } \\
\text { the total of } \\
\text { consultations }\end{array}$ & $\begin{array}{c}\text { Proportion of the } \\
\text { total of eyes } \\
\text { consultations }\end{array}$ \\
\hline H00 & Hordeolum and chalazion & $0.063 \%$ & $4.876 \%$ \\
H01 & Other inflammation of eyelid & $0.043 \%$ & $3.328 \%$ \\
H02 & Other disorders of eyelid & $0.028 \%$ & $2.167 \%$ \\
H03 & Disorders of eyelid in diseases classified elsewhere & $0.001 \%$ & $0.077 \%$ \\
H04 & Disorders of lacrimal system & $0.032 \%$ & $2.477 \%$ \\
H05 & Disorders of orbit & $0.007 \%$ & $0.542 \%$
\end{tabular}




\begin{tabular}{|c|c|c|c|}
\hline H06 & $\begin{array}{l}\text { Disorders of lacrimal system and orbit in diseases classified } \\
\text { elsewhere }\end{array}$ & $0.003 \%$ & $0.232 \%$ \\
\hline H10 & Conjunctivitis & & \\
\hline H10.0 & Mucopurulent conjunctivitis & $0.055 \%$ & $4.257 \%$ \\
\hline H10.4 & Chronic conjunctivitis & $0.072 \%$ & $5.573 \%$ \\
\hline H10.5 & Blepharoconjunctivitis & $0.023 \%$ & $1.780 \%$ \\
\hline H10.8 & Other conjunctivitis & $0.023 \%$ & $1.780 \%$ \\
\hline H10.9 & Conjunctivitis, unspecified & $0.149 \%$ & $11.533 \%$ \\
\hline H11 & Other disorders of conjunctiva & $0.259 \%$ & $20.046 \%$ \\
\hline H13 & Disorders of conjunctiva in diseases classified elsewhere & $0.007 \%$ & $0.542 \%$ \\
\hline H15 & Disorders of sclera & $0.005 \%$ & $0.387 \%$ \\
\hline H16 & Keratitis & $0.034 \%$ & $2.632 \%$ \\
\hline H17 & Corneal scars and opacities & $0.008 \%$ & $0.619 \%$ \\
\hline H18 & Other disorders of cornea & $0.016 \%$ & $1.238 \%$ \\
\hline H19 & Disorders of sclera and cornea in diseases classified elsewhere & & \\
\hline H19.3 & $\begin{array}{l}\text { Keratitis and keratoconjunctivitis in other diseases classified } \\
\text { elsewhere }\end{array}$ & $0.001 \%$ & $0.077 \%$ \\
\hline H19.8 & $\begin{array}{l}\text { Other disorders of sclera and cornea in diseases classified } \\
\text { elsewhere }\end{array}$ & $0.000 \%$ & $0.000 \%$ \\
\hline H20 & Iridocyclitis & $0.009 \%$ & $0.697 \%$ \\
\hline H21 & Other disorders of iris and ciliary body & $0.003 \%$ & $0.232 \%$ \\
\hline H22 & $\begin{array}{l}\text { Disorders of iris and ciliary body in diseases classified } \\
\text { elsewhere }\end{array}$ & $0.001 \%$ & $0.077 \%$ \\
\hline H26 & Other cataract & $0.082 \%$ & $6.347 \%$ \\
\hline H28 & $\begin{array}{l}\text { Cataract and other disorders of lens in diseases classified } \\
\text { elsewhere }\end{array}$ & $0.003 \%$ & $0.232 \%$ \\
\hline H30 & Chorioretinal inflammation & $0.005 \%$ & $0.387 \%$ \\
\hline H31 & Other disorders of choroid & $0.004 \%$ & $0.310 \%$ \\
\hline H32 & Chorioretinal disorders in diseases classified elsewhere & $0.001 \%$ & $0.077 \%$ \\
\hline H33 & Retinal detachments and breaks & $0.017 \%$ & $1.316 \%$ \\
\hline H34 & Retinal vascular occlusions & $0.004 \%$ & $0.310 \%$ \\
\hline H35 & Other retinal disorders & $0.041 \%$ & $3.173 \%$ \\
\hline H36 & Retinal disorders in diseases classified elsewhere & $0.015 \%$ & $1.161 \%$ \\
\hline H43 & Disorders of vitreous body & $0.009 \%$ & $0.697 \%$ \\
\hline H44 & Disorders of globe & $0.026 \%$ & $2.012 \%$ \\
\hline H45 & $\begin{array}{l}\text { Disorders of vitreous body and globe in diseases classified } \\
\text { elsewhere }\end{array}$ & $0.001 \%$ & $0.077 \%$ \\
\hline H53 & Visual disturbances & $0.141 \%$ & $10.913 \%$ \\
\hline H54 & $\begin{array}{l}\text { Visual impairment including blindness (binocular or } \\
\text { monocular) }\end{array}$ & $0.101 \%$ & $7.817 \%$ \\
\hline \multicolumn{2}{|r|}{ Total Eyes } & $1.292 \%$ & $100 \%$ \\
\hline
\end{tabular}




\begin{tabular}{|c|c|c|c|}
\hline \multicolumn{4}{|c|}{ Endocrine system diseases (E00-E90) } \\
\hline Code & Specification & $\begin{array}{l}\text { Proportion of } \\
\text { the total of } \\
\text { consultations }\end{array}$ & $\begin{array}{c}\text { Proportion of the } \\
\text { total of endocrine } \\
\text { consultations }\end{array}$ \\
\hline E02 & Subclinical iodine-deficiency hypothyroidism & $0.006 \%$ & $0.763 \%$ \\
\hline E03 & Other hypothyroidism & $0.510 \%$ & $64.885 \%$ \\
\hline E04 & Other nontoxic goitre & $0.058 \%$ & $7.379 \%$ \\
\hline E05 & Thyrotoxicosis [hyperthyroidism] & $0.034 \%$ & $4.326 \%$ \\
\hline E06 & Thyroiditis & $0.018 \%$ & $2.290 \%$ \\
\hline E07 & Other disorders of thyroid & $0.014 \%$ & $1.781 \%$ \\
\hline E20 & Hypoparathyroidism & $0.003 \%$ & $0.382 \%$ \\
\hline E21 & $\begin{array}{l}\text { Hyperparathyroidism and other disorders of parathyroid } \\
\text { gland }\end{array}$ & $0.002 \%$ & $0.254 \%$ \\
\hline E22 & Hyperfunction of pituitary gland & $0.033 \%$ & $4.198 \%$ \\
\hline E23 & Hypofunction and other disorders of pituitary gland & $0.019 \%$ & $2.417 \%$ \\
\hline E24 & Cushing's syndrome & $0.002 \%$ & $0.254 \%$ \\
\hline E25 & Adrenogenital disorders & $0.001 \%$ & $0.127 \%$ \\
\hline E26 & Hyperaldosteronism & $0.001 \%$ & $0.127 \%$ \\
\hline E27 & Other disorders of adrenal gland & $0.003 \%$ & $0.382 \%$ \\
\hline E28 & Ovarian dysfunction & $0.040 \%$ & $5.089 \%$ \\
\hline E29 & Testicular dysfunction & $0.005 \%$ & $0.636 \%$ \\
\hline E30 & Disorders of puberty, not elsewhere classified & $0.008 \%$ & $1.018 \%$ \\
\hline E31 & Polyglandular dysfunction & $0.001 \%$ & $0.127 \%$ \\
\hline E32 & Diseases of thymus & $0.002 \%$ & $0.254 \%$ \\
\hline E34 & Other endocrine disorders & $0.024 \%$ & $3.053 \%$ \\
\hline E35 & $\begin{array}{l}\text { Disorders of endocrine glands in diseases classified } \\
\text { elsewhere }\end{array}$ & $0.002 \%$ & $0.254 \%$ \\
\hline \multicolumn{2}{|r|}{ Total Endocrine } & $0.786 \%$ & $100 \%$ \\
\hline
\end{tabular}

\begin{tabular}{|c|l|c|}
\hline \multicolumn{2}{|c|}{ Abnormalities during pregnancy (O00-O08) } \\
\hline Code & \multicolumn{1}{|c|}{ Specification } & $\begin{array}{c}\text { Proportion of the } \\
\text { total of } \\
\text { consultations }\end{array}$ \\
\hline O01 & Hydatidiform mole & $0.002 \%$ \\
$\mathbf{O 0 2}$ & Other abnormal products of conception & $0.020 \%$ \\
$\mathbf{O 0 3}$ & Spontaneous abortion & $0.066 \%$ \\
$\mathbf{O 0 4}$ & Medical abortion & $0.005 \%$ \\
$\mathbf{O 0 5}$ & Other abortion & $0.006 \%$ \\
$\mathbf{O 0 6}$ & Unspecified abortion & $0.033 \%$ \\
$\mathbf{O 0 7}$ & Failed attempted abortion & $0.001 \%$ \\
$\mathbf{O} 08$ & Complications following abortion and ectopic and molar pregnancy & $0.002 \%$
\end{tabular}




\begin{tabular}{|c|c|}
\hline- & $\begin{array}{l}\text { Non registered abortion, identified according the prenatal consultations (we } \\
\text { identify an abortion if the mother assists to a prenatal control, but the } \\
\text { difference between this prenatal control and the previous is more than } 10 \\
\text { months). }\end{array}$ \\
\hline
\end{tabular}

Notes: Codes reported until the second digit include all the successive 3-digit diagnosis. Codes reported until the third digit in the tables were included individually.

\section{Appendix B}

\section{Cleaning the RIPS database}

Table 7 reports the initial distribution of the observations in the database of hospitalization, emergency room and doctor visits for each year of the panel. There are 85 million observations for the period 2003-2007.

Table 5. Initial distribution of the observations in the RIPS database

\begin{tabular}{|c|c|}
\hline Year & Observations \\
\hline $\mathbf{2 0 0 3}$ & 15604624 \\
\hline $\mathbf{2 0 0 4}$ & 13028608 \\
\hline $\mathbf{2 0 0 5}$ & 18232997 \\
\hline $\mathbf{2 0 0 6}$ & 20136840 \\
\hline $\mathbf{2 0 0 7}$ & 18857543 \\
\hline Total observations & 8560612 \\
\hline
\end{tabular}

We now describe the five criteria used to clean the database.

1. Eliminate inconsistency by gender: The person appears several times in the panel (with the same id), but his/her gender is not consistent over time.

2. Eliminate inconsistency in age: The person appears several times in the panel (with the same id), but there are inconsistent age gaps from one year to the next or between years.

3. Flag and Eliminate individuals who appear frequently in the database and do not seem to suffer from a chronic disease: We identify individuals that appear more than 40 times in the panel, but less than half of all visits correspond to the same diagnose. ).

4. Eliminate by invalid year or type of regime: The observations belong to a year that is not covered by the panel (which goes from 2003 to 2007) or the observations belong to a non-valid type of regime (valid types of regime are: 1contributive, 2-subsidized, 3-uninsured, 4-particular, 5-other, 6-displaced). 
5. Eliminate observations which have an invalid municipal or state code. Given that we would not be able to link this observation with the level aerial spraying, eradication or coca cultivation.

Table 7 reports the number of observations resulting after each stage of the cleaning process for each year in the panel, as well as the changes in the total number of observations in each stage. After cleaning the data we end with 75 million observations.

Table 7. Resulting observations after each stage of the cleaning process of the database.

\begin{tabular}{|c|c|c|c|c|c|c|c|}
\hline Cleaning stage & $\mathbf{2 0 0 3}$ & $\mathbf{2 0 0 4}$ & $\mathbf{2 0 0 5}$ & $\mathbf{2 0 0 6}$ & $\mathbf{2 0 0 7}$ & $\mathbf{T O T A L}$ & $\begin{array}{c}\text { Observations } \\
\text { dropped in this } \\
\text { stage }\end{array}$ \\
\hline $\begin{array}{c}\text { By gender } \\
\text { inconsistencies }\end{array}$ & 15408574 & 13028608 & 17918396 & 19803524 & 18623556 & $\mathbf{8 4 7 8 2 ~ 6 5 8}$ & 1077954 \\
\hline $\begin{array}{c}\text { By age } \\
\text { inconsistencies }\end{array}$ & 13065370 & 13028608 & 16301634 & 16841509 & 16987106 & $\mathbf{7 6 ~ 2 2 4 ~ 2 2 7}$ & 8558431 \\
\hline $\begin{array}{c}\text { By high } \\
\text { repetition of } \\
\text { individual }\end{array}$ & 13052128 & 12973000 & 16284020 & 16721287 & 16694323 & $\mathbf{7 5 7 2 4} \mathbf{7 5 8}$ & 499469 \\
\hline $\begin{array}{c}\text { By invalid year / } \\
\text { type of regime }\end{array}$ & 13052128 & 12967138 & 16284020 & 16721287 & 16694322 & $\mathbf{7 5 7 1 8 ~ 8 9 5}$ & 5863 \\
\hline $\begin{array}{c}\text { By invalid } \\
\text { municipal / state } \\
\text { code }\end{array}$ & 13052072 & 12965277 & 16281153 & 16721266 & 16693781 & $\mathbf{7 5 7 1 3 5 4 9}$ & 5346 \\
\hline
\end{tabular}

